This item was submitted to Loughborough's Research Repository by the author.

Items in Figshare are protected by copyright, with all rights reserved, unless otherwise indicated.

\title{
Recurring themes in the legacy of Jens Rasmussen
}

\section{PLEASE CITE THE PUBLISHED VERSION}

http://dx.doi.org/10.1016/j.apergo.2016.10.002

\section{PUBLISHER}

(C) Elsevier

\section{VERSION}

AM (Accepted Manuscript)

\section{PUBLISHER STATEMENT}

This work is made available according to the conditions of the Creative Commons Attribution-NonCommercialNoDerivatives 4.0 International (CC BY-NC-ND 4.0) licence. Full details of this licence are available at: https://creativecommons.org/licenses/by-nc-nd/4.0/

\section{LICENCE}

CC BY-NC-ND 4.0

\section{REPOSITORY RECORD}

Waterson, Patrick, Jean-Christophe Le Coze, and Henning Boje Andersen. 2019. "Recurring Themes in the Legacy of Jens Rasmussen". figshare. https://hdl.handle.net/2134/24054. 


\title{
Recurring Themes in the Legacy of Jens Rasmussen
}

\author{
Patrick Waterson ${ }^{1}$, Jean-Christophe Le Coze ${ }^{2}$ and Henning Boje Andersen ${ }^{3}$ \\ ${ }^{1}$ Human Factors and Complex Systems Group, \\ Loughborough University Design School, \\ Loughborough University, \\ Loughborough, LE11 3TU, \\ United Kingdom. \\ ${ }^{2}$ Institut National de l'Environnement \\ Industriel et des Risques (INERIS), Parc Alata, \\ 60550 Verneuil en Halatte, France \\ ${ }^{3}$ DTU Management Engineering, \\ Technical University of Denmark \\ Centrifugevej 2800 Kgs. Lyngb, Denmark.
}

\section{Address for correspondence:}

Dr. Patrick Waterson,

Human Factors and Complex Systems Group, Loughborough University Design School, Loughborough University, Loughborough, LE11 3TU, United Kingdom.

Tel: 01509228478

Fax: 01509223940

Email: p.waterson@lboro.ac.uk 


\section{Introduction}

The work of Jens Rasmussen over the course of the last half century represents some of the most influential contributions to the fields of cognitive science, human factors, ergonomics and safety science. His work has inspired researchers and practitioners in a number of fields including psychology, organisational behaviour, engineering and sociology (Le Coze, 2015; this issue). Early work on the Skills, Rules, and Knowledge taxonomy for example, was instrumental in fostering the development of models of human error during the 1980s and 90s (e.g. Norman, 1981; Reason, 1990). In more recent years, a large amount of research has drawn on theoretical and practical aspects of Rasmussen's work including his models of the boundaries of safe operation, ecological interfaces and methods such as cognitive work analysis. Rasmussen's work on the Risk Management Framework (Rasmussen, 1997) has been cited over 1000 times since its original publication in 1997 and the extent of his influence across the wider research community is growing at a fast rate (Wears, this issue). His research has taken on renewed relevance and importance in the light of recent large-scale systems disasters and accidents (e.g. Fujushima Daiichi, Deepwater Horizon, and South Korea Ferry Disaster - Jun et al and Lee et al., this issue), as well as recent developments in the fields of normal accident theory (Perrow, 1984), resilience engineering (Hollnagel et al., 2006) and the high reliability organisation (Weick and Sutcliffe, 2006; Le Coze, 2016a, this issue).

\section{Origins and aims of the special issue}

The idea for the collection of papers in this special issue first came about through a conversation between two of the editors (PW and HBA) at a meeting of the Resilience Healthcare Network in Middelfart, Denmark in June 2012. Both of us agreed that there was a need to provide opportunities for researchers to discuss the work of Jens Rasmussen and the subsequent impact he has had upon research carried out in the last few decades since the publication of a Festschrift in 1988 (Goodstein, Andersen and Olsen, 1988). The third editor (JCLC) was involved in independently exploring Rasmussen's work (Le Coze, 2015, this issue) and helped to organise together with the other editors in August 2014 a two day symposium entitled 'The legacy of Jens Rasmussen' at the ODAM 2014 conference in Copenhagen, Denmark (www.odam2014.org/Legacy). The second 
day of the symposium took place at Risø and a total of 31 participants drawn from the USA, Australia and Europe took part and ten papers were presented. In addition, we were contacted by a number of other prominent authors in the fields of human factors and safety science who were unable to attend the symposium, but expressed in contributing to the special issue. The symposium captured elements of Rasmussen's past work, as well as new directions and developments based on his work and much of this is captured in the current special issue.

A key aim of the special issue is to re-examine the work of Jens Rasmussen in the light of recent developments in human factors and safety science. A second aim is to examine the future of human factors as it applies to safety, accidents and human error. In this editorial we first provide some further details on the life and work of Jens Rasmussen and major developments in his career (section 3). Section 4 of the editorial attempts to put Rasmussen's work into a broader context through looking at the development of four of influential publications across the period 1974-1997. Based on the analysis of these and other publications, alongside the contributions from the 15 papers in the special issue, we identify a set of recurrent themes in the Rasmussen legacy which are discussed in Section 5 of the editorial. A final section (section 6) points the way forward to future plans by the authors and others to further celebrate and continue on with Rasmussen's legacy. We are also very grateful for a final paper provided by Penny Sanderson and Cathy Burns which provides further reflections on the legacy and the papers in the special issue.

\section{Jens Rasmussen: a brief overview of his life and work}

After his M.Sc. degree in electronic engineering in 1950 and a few years at the Radio Receiver Research Laboratory, Rasmussen was recruited, in 1956, by the Atomic Energy Commission to prepare the design of the control room for the then planned nuclear research reactor at Risø, a small peninsula in Roskilde Fjord in Denmark. A few years later, at the age of 36, Jens was appointed head of the Electronics Department at the Atomic Research Establishment Risø (later Risø National Laboratory) - a position he held for 25 years until he was appointed Research Professor at the Technical University of Denmark and at Risø. 
From the very beginning as department head, Rasmussen's primary responsibilities were to lead the instrumentation of the control room and support the development and maintenance of the various scientific measurement equipment of the facility, and most of his work during the first five to six years was focused on largely technical aspects and reliability. During this time he became gradually increasingly interested in the interplay between operators and the instrumentation, cognitive requirements to displays and, indeed, operators' reactions and behaviour under abnormal conditions, revealed in the titles of some of his early papers from this period: 'Man-Machine Communication in the Light of Accident Records' (1968) and 'On the Communication between Operators and Instrumentation in Automatic Process Plants' (1969). Appendix 1 highlights some milestones in the development of Rasmussen's ideas about the role of design and human operators in system safety. Further details both of the history of Cognitive Engineering at Risø and the larger worldwide context in which this took place (e.g. the Three Mile Island and Chernobyl nuclear accidents) are provided in other publications by Vicente (1997), Nielson (1998) and Sheridan (2003; this issue). We should also note that Kant (this issue) provides an in-depth treatment of Rasmussen’s work over the period 1961-1986.

\section{A closer look at four influential papers}

The papers in this section of the editorial were selected in order to show the progression of Rasmussen's thought over three decades. Each of the papers is summarised, followed by an attempt to link them to either similar work during that decade or later work research which has been directly or indirectly influenced by the paper. We should emphasise that summarising and assessing the implications of Rasmussen's work is not an easy task. His work is often grounded in a larger philosophical and conceptual context and reflects deep and wide reading across a diverse and extensive range of disciplines. Likewise, papers written over 40 years ago resonate with current developments in the fields of human factors/ergonomics and safety science. Our principle aim in the current paper was to capture some of our own impressions of the papers and the influence they have had.

4.1 Mental procedures in real-life tasks: A case study of electronic trouble shooting (Rasmussen and Jensen, 1974, Ergonomics 17, 3, 293-307) 


\subsubsection{Summary}

This paper provides an account of the use of 'protocol analysis' to explore the mental processes involved in problem solving by electronic technicians. In the late 1960s and early 1970s the analysis of verbal protocols from operators as they carried out their tasks (e.g. process control operations) became popular amongst research workers (e.g. Bainbridge, 1969; Bainbridge and Sanderson, 1996). Rasmussen and Jensen observed the process technicians used when diagnosing problems with electronic instruments (e.g. oscilloscopes, TV displays). The paper, although written in the early 1970s is interesting for a number of reasons, not least the way in which it anticipates later developments in Rasmussen's thinking, but also subsequent developments and trends in cognitive science and human factors. For example, the study showed that the most common form of problem solving involved "topographic search": technicians organised their search for the fault based on the physical layout of the circuitry. Fault finding involved an iterative process of making good or bad judgements until they had identified the problem with the circuit. The process, although involving many redundant tests, took little time and was generally efficient. The process was also efficient in terms of the load it placed on working memory; technicians took advantage of the natural constraints built into the task (i.e. the wiring typography) and were able to offload some of the computational demands on the search. Naikar (this issue) provides an interesting example of some of the original illustrations from the Risø technical reports (Naikar, this issue,) which gives some sense of the nature of the complex problem solving (interweaving purposive and physical properties of the task) they were carrying out.

\subsubsection{Relation to other work}

This account of problem solving contrasts with the classical information processing models which were dominant at the time (e.g. Newell and Simon, 1972; Lindsay and Norman, 1972) and emphasised a set-by-step problem process which relied more on internally stored representations of the problem. Rasmussen's and Jensen's paper by contrast, acknowledges the role played by external representations in structuring the problem space (Newell, 1980). From this point of view actions and reasoning unfold as an integrated and continuous flow, where no discrete actions and decisions are taken separately (Carim Jr. et 
al., 2016). One of the characteristics of the study, and something which might be said to be recurring theme in Rasmussen's work (section 5 of this paper), is that it on the one hand harks back to earlier work which emphasises the role played by the environment on cognition and the inter-relationships between various data sources and mental representations involved in complex work tasks (in the case of this paper, Bartlett, 1958 and Craik, 1943), but also crucially anticipates or points forward to later developments (e.g. 'distributed cognition' the use of graphical representations to solve problems and the theory of mental models Hutchins, 1995; Scaife and Rogers, 1996; Johnson-Laird, 1983). Similar parallels can be drawn with other parts of the paper which read today like early descriptions of the use of 'early warnings and 'weak signals' (Macrae, 2014) or implicit memory (Broadbent et al., 1986) by technicians to provide cues to likely faults:

'In some cases 'feelings' of the location of the fault are stated, which are contradictory to the observations just recorded, but nevertheless correct in agreement with information which the man, according to the earlier recorded procedure did not mention' (Rasmussen and Jensen, 1974: 296).

Finally, the paper makes a strong commitment to the importance of carrying out real-life observations of complex work, as opposed to laboratory tasks or problems. This is particularly the case in terms of the value observational work may have for the system designer and the dangers of over-rationalising how tasks may actually be carried out. The following statement from the paper also resonates with current preoccupations with the notion of 'work as done vs. work as imagined' within the 'Safety II’ movement (Hollnagel et al., 2015; Section 5):

'The system designer with his theoretical background may quite naturally value as rational the 'elegant' deductive procedure which is informationally very efficient and based upon few observations, but this criterion will not be an appropriate one to judge performance in real-life maintenance work. It is important that system designers preparing working conditions and involved with the training become aware of this difference in task formulation and performance criteria... (Rasmussen and Jensen, 1974: 306). 
4.2 Skills, rules, and knowledge; signals, signs, and symbols, and other distinctions in human performance models (Rasmussen, 1983, IEEE Transactions on Systems, Man, and Cybernetics, 13, 3, May/June, 257-266)

\subsubsection{Summary}

In contrast to the detailed protocol analysis of technician's problem solving provided in Rasmussen and Jensen (1974), this paper offers a much more conceptual and philosophically grounded account of what Rasmussen refers to as 'the human as data processor' (Rasmussen, 1983, p. 261). As illustrated by a well-known quote from Herbert Simon (the 'ant on the beach' example) in an earlier report (Rasmussen, 1974) the behaviour of the human data processor is seen to be influenced more by external representations than by internal, cognitive constraints:

"An ant, viewed as a behaving system, is quite simple. The apparent complexity of its behaviour over time is largely a reflection of the complexity of the environment in which it finds itself "(Simon, 1969, p. 25)

In the paper Rasmussen distils from a number of sources including philosophy (e.g. Plato, Alfred North Whitehead, Daniel Dennett and Gregory Bateson), human factors (e.g. Crossman and Cooke, 1962; Fitts and Posner, 1962), architecture and design (e.g. Alexander. 1964) and cybernetics (e.g. Rosenblueth et al., 1943) the view that human behaviour is fundamentally teleological, that is, driven by purposive goals and shaped by signals, signs and symbols in the environment:

“... meaningful interaction with an environment depends upon the existence of a set of invariate constraints in the relationships among events in the environment and between human actions and their effects.” (Rasmussen, 1983, p. 258).

Building upon earlier taxonomies of knowledge and skill development (e.g. Fitts and Posner, 1962), Rasmussen suggests that it is possible to identify three different style or modes of processing (skill-, rule- and knowledge-based - figure 1) which are associated with three types of mappings (signals, signs and symbol). Skill-based processing involves the perceptual motor system and uses signals (defined as 'continuous quantitative indicators of the time-space behaviour of the 
environment' Rasmussen, 1983: 260) to carry out tasks such as experimental tracking tasks, assembly tasks and others involving optical flow.

Figure 1 about there

Rule-based processing is guided more by stored rules or procedures associated with a familiar situation (e.g. a set of instructions which have been followed many times and are stored in long-term memory). Information at the rule-based level of processing is typically perceived as signs - situations, which derive from convention or prior experience. Signs contrast with signals in that the latter refer to internal conceptual representations analogous to schema (Bartlett, 1932; Schank and Abelson, 1977), cognitive frames (Minsky, 1975) or mental models (Johnson-Laird, 1983). Signals are also associated with the third type of cognitive processing which Rasmussen characterises as knowledge-based. Knowledge-based processing takes place when a goal is explicitly formulated, which then triggers a plan which is subsequently tested against the original goal. The operation of knowledge-based processing is similar, but more developed and detailed, with regard to other attempts to characterise goal-based problem solving (e.g. the 'Test - Operate - Test - Exit' (TOTE) strategy described by Miller et al., 1960).

A key feature of the paper is the description of the abstraction hierarchy (figure 2), which attempts to operationalise the system's functional properties and how these relate to the various levels of operator's cognitive processing (Skills, Rules and Knowledge - the SRK framework). The abstraction hierarchy, alongside a number of other models and frameworks developed by Rasmussen over the period 1960 to 2000 (e.g. the decision ladder) also filled an important gap relative to other work within cognitive psychology, human error and accidents:

"In the early 1960s, we realized from analyses of industrial accidents the need for an integrated approach to the design of human-machine systems. However, we very rapidly encountered great difficulties in our efforts to bridge the gap between the methodology and concepts of control engineering and those from 
various branches of psychology ... It appeared to be necessary to start our own selective research program to find models useful for engineering design." (Rasmussen, 1986)

Figure 2 about here

Aside from the abstraction hierarchy, the paper also provides some important insights into Rasmussen's thinking about system design and the importance of qualitative, as compared to quantitative models of human performance (Sheridan, this issue). In the case of system design, Rasmussen argues that 'models of man' such as the abstraction hierarchy (figure 2) are needed in order to cope with the increasing complexity of modern work environments and the variety of professional contexts in which work takes place:

“... in ordinary working life, human interaction is based on a top-down prediction drawn from perceptions of other people's intentions, motives and on common sense representations of human capabilities, together with knowledge of accepted practice ... the most important information to use for planning human interaction for unfamiliar occasions is therefore knowledge of value structures and myths of the work environment." (Rasmussen, 1983, p. 263)

This statement sets the stage for later work by Rasmussen and others (e.g. Rasmussen, 1990; Svedung and Rasmussen, 2000) which seeks to probe deeper into the role played by aspects of organisational culture, government policy and regulation in contributing to large-scale accidents and disasters (e.g. Kirwan et al., 2002; Guldenmund, 2000; Hall, 1999). Notably, the work also draws on work in philosophy and the cognitive sciences which was popular at the time (e.g. Daniel Dennett's work on intentional systems; Dennett, 1971), as well as pointing the way forward to more recent work which has looked at embodied cognition (Clark, 1997). A final important note to make about the 1983 paper is that Rasmussen stresses the importance of studying 'real-life situations' (p. 265) in order to identify human performance criteria. Likewise he places emphasis on the need for conceptual analysis which crosses disciplinary boundaries (p. 266). 


\subsubsection{Relation to other work}

The 1983 paper alongside other work published by Rasmussen in the 1980s (e.g. Rasmussen, 1985, 1986) has had an enormous influence on the course of subsequent work within human factors/ergonomics, cognitive science and many other disciplines. Ultimately this body of research in itself led up to the formation of a new set of disciplines ('Cognitive Systems Engineering', Rasmussen et al., 1994; Hollnagel and Woods, 1983; 'Cognitive Engineering', Norman, 1986), as well as a family of methods for work analysis and design ('Cognitive Work Analysis', Vicente, 1999; Naikar, this issue; 'Accimaps', Waterson et al., this issue; Salmon et al., this issue; Jun et al., this issue; Lee et al, this issue; STAMP - Leveson, this issue). The SRK framework and Abstraction Hierarchy were brought together in later work in the 1980s to form 'Ecological Interface Design' (EID - Rasmussen and Vicente, 1989; Vicente and Rasmussen, 1992). EID embodies elements of James Gibson's ecological psychology, in particular the view that system design should create a 'virtual ecology' (Bennett, this issue) mapping elements of the work system to human (e.g. skills, rules and knowledge) and system constraints (e.g. affordances, visual cues - Bennett and Flach, 2011). Over the past few decades EID has exerted a major influence, both in terms of advancing our theoretical understanding of complex work environments, as well as in terms of spawning a range of practical tools and methods for work analysis (e.g. the ‘decision' or 'step ladder' ladder model of problem solving; Hunt and Rouse, 1984; McIlroy and Stanton, 2015; Hilliard and Jamieson, this issue).

A second area, in which the 1983 paper, alongside others from that decade exerted influence, was in the development of categorisation schemes and frameworks for human error and the control of attention. Reason's Generic Error-Modelling System (GEMS, Reason, 1987) for example, uses the SRK framework to construct a framework capable of locating cognitive limitations and biases (e.g. execution failures, slips and lapses), as well as higher-level problem solving failure which contribute to the occurrence of errors and mistakes within modern contexts of work. Similarly, Norman's development of a categorisation scheme for actions slips (Norman, 1981) and their relationship to the automatic control of behaviour (Norman and Shallice, 1986) were 
subsequently much influenced by Rasmussen's earlier work. From a historical point of view it is interesting to note that in an age before the arrival of email, social media and the internet, collaborations between research based in Europe and the US were much bolstered by meetings sponsored by bodies such as NATO, the World Bank and other national organisations (e.g. the NATO sponsored workshop on human error held in Italy in 1985 where Rasmussen, Reason and Norman presented papers - Hollnagel et al., 1986).

4.3 Human error and the problem of causality in analysis of accidents (Rasmussen, 1990, Philosophical Transactions of the Royal Society London, B 327, 449-462)

\subsubsection{Summary}

This paper was written as part of larger special issue of the Philosophical Transactions of the Royal Society on 'Human factors in high-risk situations' and includes other papers from James Reason, Donald Broadbent and Donald Norman amongst others. As is perhaps fitting with the title of the journal, the paper provides a philosophical account of human error and accident causation, whilst at the same time expanding the scope of Rasmussen's views on the failure of large-scale systems and safety. In particular, there is an emphasis within the paper on the 'boundaries of safe performance' and factors which shape the degree to which repeated patterns of failure pathways occur. In common with many papers authored by Rasmussen, a particular emphasis in the paper is on the terminology used to describe human error and accidents. For example, Rasmussen draws on the distinction between 'types' and 'tokens' in accident causation (Wagenaar and Reason, 1990). Accidents 'types' refers to permanent weaknesses ('resident pathogens' to use Reason's terminology; Reason, 1990) which may be present within a complex system or organisations. 'Tokens' by contrast are the temporary, individually defined events which directly contribute to an accident (e.g. the actions of an operator which trigger a series of other events preceding an accident). The distinction is important because it leads Rasmussen to view accidents not simply as a sequence of failed events which may be over-interpreted given the likelihood of hindsight bias. Rather, an alternative frame of reference is adopted in the paper, namely that accidents 
should be seen from the point of view of the breakdown of 'normal practice' and operation.

These ideas link back to his earlier work on fault finding by electronics technicians, but also are very close to current debates centred on resilience engineering (e.g. Hollnagel et al., 2006), organisational learning (Argote, 1999) and the high reliability organisation (Weick and Sutcliffe, 2007; Harvey et al., in press):

“... design must be based on models that are able to predict the effects of technical faults and human errors during operation and to evaluate the operating organisation to cope with such disturbances." (Rasmussen, 1990:1)

Maintaining safety and preventing system breakdown involves focusing on error types and not tokens and adopting a proactive stance towards risk and hazard management (Leplat and Rasmussen, 1984). From this point of view error can be seen as a 'normal' by-product of safe performance:

“...'errors' are unavoidable side effects of the exploration of the boundaries of the envelope of acceptable performance." (Rasmussen, 1990:8)

Similarly, what we would normally call 'workarounds' are not seen in a negative light or as deviations from rule-following (e.g. 'violations', Reason et al., 1998; Hale and Borys, 2013a,b) but rather as necessary 'experiments' rather like the fault finding strategies used by technicians (Rasmussen and Jensen, 1974):

"The basic issue is that human errors cannot be removed in flexible or changing work environments by improved system design or better instruction, nor should they be. Instead, the ability to explore degrees of freedom should be supported and means for recovery from the effects of errors should be found" (Rasmussen, 1990:9).

\subsubsection{Relation to other work}

The paper might be said to represent something of a 'bridge' between early work which had focused on operators and their cognition and Rasmussen's later research in the 1990s which more fully embraces on the one hand a control- 
theoretic and, on the other, the application of the systems approach towards accidents (Rasmussen, 1997, section 4.4). As Le Coze (this issue), Kant (this issue) and Leveson (this issue) point out this combined an engineering approach, as well as one that draws on a rich 'intellectual matrix' cutting across cybernetics, psychology and a range of other social sciences. This 'bridge' might be construed as one aspect of how Rasmussen attempted to tackle both 'micro-' and 'macro-' cognition and organisational levels of analysis (figure 3; Karsh et al., 2014). During the late 1980s Rasmussen was developing a much broader approach to the study of complex work environments, one that clearly involved the development of new methods, but also and perhaps crucially, the development of new ways of modelling complexity.

Figure 3 about here

A number of parallels with more recent work are also apparent and are likely to mean that the 1990 paper, although by no means the easiest of Rasmussen's to read and understand, will continue to have an influence in the future. One obvious parallel between the description of types and tokens is recent work on archetypes of organisational failure. Marais et al. (2006) for example, argue that modern organizations that operate complex systems have to make trade-offs between conflicting goals such as safety, production, delivery times and utilization of capacity. As a result of these goals, common patterns in terms of system breakdown and 'drift into failure' (Dekker, 2011) are likely to occur, something Rasmussen initially described as the 'defence in depth fallacy' (Le Coze, 2015). Such patterns share much in common with the types discussed by Rasmussen are draw on earlier work in cybernetics which would appear to be coming back into fashion (e.g. Stafford Beer's work on the Viable Systems Model - Kontogiannis and Malakis, 2012; Waterson, Baber and Li., 2016; Rid, 2016). Likewise, Rasmussen's argument that human error is an inevitable outcome of complex work environments takes on an added dimension of relevancy in the light of recent drives towards the goal of 'zero accidents' and 'zero fatalities' within occupational safety (Zwetsloot et al., 2013; Zwetsloot et 
al., 2017), as well as other debates surrounding 'just culture' and the allocation of responsibility and attributions of blame within accidents (Holden, 2009; Dekker, this issue).

4.4 Risk management in a dynamic society: a modelling problem (Rasmussen, 1997, Safety Science, 27, 2/3, 183-213)

\subsubsection{Summary}

The 1997 paper represents the culmination of a research programme began by Rasmussen in the late 1960s and ending in the late 1990s. In particular, the paper provides an overview of efforts to model complex socio-technical systems across a range of different levels of abstraction and decomposition (e.g. structural and functional). The paper begins with an account of the challenges faced by new models of risk and hazard management and the need to keep up with the fast changing pace of new technology; the scale and growth of modern industrial installations; and, the aggressive competitive environments in which organisations operate. These, together with other developments (e.g. the failure of computerised trading systems in the 1987 'Black Monday' stock market crash) constitute what Rasmussen calls the 'problem space' (page 84; Newell, 1980) and meant at the time that new risk models with a wider range of inputs from cross-disciplinary research (sociology, policy science, organisational behaviour) and levels of analysis (e.g. multi-level analysis - Hale et al., 1996) were needed. The recent global financial crisis (2007-2008) and the fact that similar calls for interdisciplinarity and further analysis of multi-level causality in accidents (Pink et al., in press; Ryan and Waterson, 2016; Waterson, Mumford and Golightly, 2016, Le Coze, 2013, 2016b) have been made recently, underline the continued relevance of the 1997 paper almost two decades years after its publication.

In order to demonstrate the needs for new models Rasmussen first considers traditional ways of modelling risk through the decomposition of the sociotechnical system into elements such as that used by task analysis (Annett and Duncan, 1967). The problem with task analysis is that according to Rasmussen, it assumes a very tightly controlled (e.g. command and control) environment where the operator is given little freedom to deviate from a sequence of pre-described actions. In arguments echoing his earlier work, he puts forward the view that 
human behaviour is much more sensitive to the task context and the 'value system' of the organisation in which the operator is working. Frameworks such as SRK by contrast (figure 2), capture and take into account these factors and provide an improved way in which to understand what can be characterised as 'naturalistic decision making' (Klein et al., 1994). Likewise, analysis by decomposition of tasks needs to view control within a wide sphere of influence involving variety of different stakeholders and actors (e.g. managers, regulators), as well as a wider set of specialisms and disciplines:

"In general, the present interest in cognitive science has brought with it a convergence of the economist's concept of 'decision making', the social concept of 'management', and a psychological concept of 'cognitive control' of human activity...” (Rasmussen, 1997: 188).

The alternative is to take a different perspective on risk and to use 'functional abstraction' to model processes involving safety and risk. This approach involves a consideration of the boundary conditions and processes which determine how these conditions drift into states which are likely to lead to accidents such as unacceptably high levels of workload or management placing too much priority on production as compared to safety. The well-known 'Brownian motion' model of the boundaries of acceptable performance (figure 4) is one of the ways in which Rasmussen chooses to graphically illustrate the dynamic interplay between levels of analysis and behaviours and actions of the various individuals and groups outside and within the system. Another methods involves the use of an early version of the Accimap method which shows the various conflicts which exist between government, regulators and company managers and staff Operators) within shipping. Later versions of this Accimap are shown for the Zeebrugge ferry accident in Rasmussen and Svedung (2000), something in the following years which inspired a wealth of interest as testified by the number of articles of this special issue on this approach (Waterson et al., this issue; Salmon et al., this issue; Jun et al., this issue; Lee et al., this issue; STAMP - Leveson, this issue). 
Figure 4 about here

The latter parts of the 1997 paper are devoted to a review of trends within the human sciences as they relate to safety and risk models current at the end of the 1990s. Rasmussen reviews this trends through a very wide and broad, but also indepth 'sweep' through work in the psychology of decision-making and economics (e.g. Tversky and Kahneman, 1974), as well as organisational behaviour (e.g. the work of James March, Herbert Simon) and ecological psychology (e.g. the work of Egon Brunswik, James Gibson, Kurt Lewin). The paper concludes with a short set of implications for future research, chief amongst these is a plea that future work will move further toward crossing interdisciplinary boundaries and shift further away from past approaches to human error:

“... convergent parallel changes of the paradigms of several disciplines are shaped by the increased interest in cognitive, intentional concepts ... replacing the past focus on mechanistic, normative approaches...” (Rasmussen, 1997:209)

\subsubsection{Relation to other work}

It is difficult to underestimate the influence the 1997 paper has had on researchers and practitioners within human factors/ergonomics, safety science and a host of other disciplines. Alongside a succession of other studies (e.g. Turner, 1978; Perrow, 1984; Reason, 1990; Kletz, 1993) the paper 'catalysed' efforts to shift the focus of studies of accident causation away from accounts focused on the individual per se and their role in 'human error', and towards a concern with the underlying organisational factors. Previous accounts in the later 1960s and early 1970s had either stressed the role played by factors such 'accident proneness' (Hale and Hale, 1972; Burnham, 2009) or focused on questions such as 'who caused the accident' as compared to 'what conditions and mechanisms have increased the possibility of it [the accident] happening?' (Robertson et al., 2016, p. 11). The 1997 paper might be also be said to typify what Borys et al., (2009) characterise as the 'fifth age of safety', namely the 'adaptive age' where the human's capability for adaptation is also the element of 
the system which enables it to sustain reliable performance in the light of adversity. A similar shift was from studies which focused in depth on safety culture in the 1980s towards research which emphasised resilience, sociotechnical systems theory and the boundaries of safe performance (Waterson et al., 2015).

An interesting parallel between Rasmussen's work on task decomposition and functional abstraction and the work of the neuroscientist and psychologist David Marr (1945-1980) is made by Flach and Voorhorst (2016) in their recent survey of the inter-relationships between cognitive science, design and psychology. Marr (1982) put forward a theory of human information processing using the following levels of analysis: (1) The computational level, at which the task and the logic of its solution is described; (2) the algorithmic level, which specifies how the information associated with the computation is represented and the procedures for performing the relevant manipulations; and (3) the implementational level, which describes how the algorithms are realized in the nervous system (Stevens, 2012). Whilst Rasmussen did not cite Marr's work in the 1997 paper, it seems highly likely that he was influenced by his approach to information processing. Flach and Voorhorst (2016:Chapter 11) argue that the abstraction hierarchy incorporates elements of Marr's approach, particularly in terms of posing questions of the work domain along the lines of 'why it functions in such a manner', 'what information is processed' and 'how it is processed.' The parallel between the work of Marr and Rasmussen leads them to conclude that each were seeking to what they term 'a metaphysical basis for describing the deep structure of situations' (Flach and Voorhorst, 2016: 224).

\section{Recurrent themes in the legacy}

Selecting a set of recurrent themes from a full and intellectually prolific career is always a difficult task. We note that Kant (this issue) extracts a similar set of themes in his paper which overlap to some extent with our own in this section. In this section we have drawn partly on the papers in the special issue, but also our own impressions of common threads running through Rasmussen's work in order to focus on eight themes. 


\section{Theme 1: Linking back to the past}

Cybernetics (e.g. the work of Norbert Wiener and Stafford Beer) clearly played an important role in Rasmussen's mindset, as for instance when moving from micro to macro description of complex systems (Figure 3). As a multidisciplinary field with strong roots in engineering, cybernetics offered a bridge between the "hard" and "soft” sciences, a bridge that helped Rasmussen conceptualise issues of assessment, design and investigation of complex systems. The self-organised and adaptive features of humans exhibiting their degree of freedom against any attempt at rationalising their behaviour offered Rasmussen a path from the study of errors at the individual level to an analysis then conceptualisation of accidents at a sociotechnical level. Similar links might be drawn to work on signal detection theory (Tanner and Swets, 1954), general systems theory (von Bertalanffy, 1969) and information and control theory (Shannon, 1948 - figure 5).

Figure 5 about here

Rasmussen also drew heavily on the work of James Gibson (1904-1979) and his approach to the ecology of perception which the role played by environmental affordances and mental models in shaping behaviour. Gibson's primary concern throughout most of his career, and prompted by his early work with the Gestalt psychologist Kurt Koffka (1886-1941), was "how do we see the world as we do?” (Dictionary of Scientific Thought, 2008). This type of functionalism shaped some of the approach that Rasmussen applied to a range of problems across his career. David Marr, as noted in section 4.4.2 above, also drew on Gibson’s work in a way which echoes Rasmussen:

"Gibson's important contribution was to take the debate away from the philosophical considerations of sense-data and the affective qualities of sensation and to note instead that the important thing about the senses is that they are channels for perception of the real world outside or, in the case of vision, of the visible surfaces. He therefore asked the critically important question, How does one obtain constant perceptions in everyday life on the basis of continually changing sensations? This is exactly the right question, showing 
that Gibson correctly regarded the problem of perception as that of recovering from sensory information "valid" properties of the external world" (Marr, 1982, p. 29; quoted in Flach and Voorhorst, 2016).

A similar lineage can be trace back to the work of Egon Brunswik (1903-1955) and his 'Lens Model' which describes the relations between the environment and the behaviour of organisms in the environment. A particular emphasis within Brunswik's work which is likely to have influenced Rasmussen, was the primacy of examining individual behaviour in naturalistic settings and seeking descriptions of behaviour rather than attempt to discover laws of behaviour (Hammond and Stewart, 2001) $)^{2}$. Work of this kind was taken up in the 1960s by Ulric Neisser (1928-2012, e.g. Neisser’s Perceptual Cycle; Neisser, 1967, 1976), Jerome Bruner (1915-2016, Bruner, 1973, 1986) and alongside more traditional engineering-oriented and experimental approaches to the study of cognition (e.g. Bartlett, Craik, Simon) made up much of the rich texture of Rasmussen's subsequent work in the 1970s and beyond.

\section{Theme 2: Setting an agenda for the future}

In the process of reading many of Rasmussen's papers it is difficult not to be struck by how many ideas of his from the past have influenced either directly or indirectly the course of later work within human factors/ergonomics and safety science. It is hard to imagine, for example, how the progress that was made within the field of the study of human error during the 1980s and 90s could have been achieved without his influence (e.g. the impact of the SRK framework on models of error). Similarly, as discussed in section 4.1.2, some of his earliest work in the 1960s and 1970s paved the way for recent work on resilience engineering and what might be called the 'normalisation of error' (e.g. safety I vs. safety II - Hollnagel et al, 2015) movement (theme 5). Le Coze (this issue) argues that much of Rasmussen's work has promoted what he terms the 'constructivist turn' in safety science, whilst Leveson (this issue) vies his work as bringing about a 'paradigm change' in engineering for safety. Finally, Flach (this issue) places Rasmussen's work within a much larger semiotic context. The

\footnotetext{
2 It is interesting to note the parallels between the work of Brunswik and Rasmussen - both combined an interest in the philosophy of science, the interaction between cognition and the environment and the importance of studies carried out in 'real world' settings - Gregory, (1987).
} 
fact that Rasmussen's work can generate these types of claims is testament to the role his work has had in setting a research and practice agenda far into the future.

\section{Theme 3: Models, diagrams and frameworks}

Rasmussen's engineering epistemology might be said to be based on a set of powerful visual heuristics which underpinned his intellectual message. As Cook (2014) pointed out in a presentation at the ODAM Legacy Symposium, Rasmussen's back ground was in electronic and engineering where visual representations (e.g. 'indicator diagrams) are common. Research which has examined the work of the engineering profession in more depth, has concluded that engineering work is rooted in the use of non-verbal representations and experience-based forms of cognition (Ferguson, 1992). One of the appeals of the SRK framework, decision ladder, 'Brownian motion model', as well as methods such as Cognitive Work Analysis and Accimaps, is that they are highly visual and afford the mapping of complex ideas and constructs. Likewise, their aesthetic content and ability to convey immediately an intuitive grasp of patterns and inter-relationships are amongst the features that have contributed to their long lasting influence. Because we think with the help of images, his drawings help us to reflect deeply beyond words (Larkin and Simon, 1987). Waterson et al. (this issue) also argue that one of the strengths of some of the visual diagrams and representations, particularly those associated with methods such as Accimaps, support a process of ideation, brainstorming and 'bricologe' (LéviStrauss, 1966), which may afford them advantages over other methods of accident analysis (Li et al., in preparation).

\section{Theme 4: Functionalism and the 'ecology of work'}

Engineering and cybernetics influences combined to frame Rasmussen's holistic approach to phenomena. Distinguishing the structural versus the functional perspectives of psychology, Rasmussen rarely abstracted processes from their real life context, which meant that cognition could not be studied in experimental circumstances without altering what made its specificity. This led to the ecological view of error as opposed to the taxonomic one (e.g. Reason, 1990). Similarly, safety or accidents had to be understood as resulting from holistic interactions of individuals in multiple contexts and sometimes aggregated in 
unexpected patterns (Rasmussen and Batstone, 1991). At the heart of the numerous descriptions of functional, abstraction and other types of hierarchies and categories of knowledge which take place within Rasmussen’s work (see sections 4.2 and 4.4 for example), is a concern with what Flach and Voorhorst (2016, p. 184) refer to as the 'problem ecology' of 'deep structure' of work situations. Different conceptual schemes, frameworks and 'lenses' (e.g. functional, analytical - section 4.4.2) are needed in order to dig deeper into what on the face of it may seem like routine work, but is in fact complex and multidimensional (e.g. akin to the work of the technician - section 4.1). At the end of the SRK paper (section 4.2) for example, invokes the example of Eddington's parable about the Ichthyologist (Eddington, 1939) ${ }^{3}$ in order to underline the importance of this type of conceptual analysis, as compared to experimentation followed by subsequent data analysis alone.

\section{Theme 5: 'Normal operation, normal accidents'}

Rasmussen developed a specific interpretation of the 'normality of accidents', which was initially framed by Perrow (1984). Rasmussen's interpretation relied, here again, on the self-organised and adaptive properties of individuals in complex systems (Le Coze, 2015, forthcoming). The consequence of this was translated in an imperative for the study of daily operation "risk management can only be discussed in depth when considering carefully the decision making involved in the normal operation of the hazardous processes posing potential for major accidents." (Rasmussen and Svedung, 2000). It is an interpretation that has become extremely successful in safety and accident theories, for example as popularised by Snook's (2000) account of the shooting down of the Black Hawk Friendly Fire incident in Iraq: "[the accident] was normal because it occurred as

\footnotetext{
${ }^{2}$ The parable is wroth quoting in full: "Let us suppose that an ichthyologist is exploring the life of the ocean. He casts a net into the water and brings up a fishy assortment. Surveying his catch, he proceeds in the usual manner of a scientist to systematise what it reveals. He arrives at two generalisations: No sea-creature is less than two inches long. (2) All seacreatures have gills. These are both true of his catch, and he assumes tentatively that they will remain true however often he repeats it. In applying this analogy, the catch stands for the body of knowledge which constitutes physical science, and the net for the sensory and intellectual equipment which we use in obtaining it. The casting of the net corresponds to observation; for knowledge which has not been or could not be obtained by observation is not admitted into physical science. An onlooker may object that the first generalisation is wrong. "There are plenty of sea-creatures under two inches long, only your net is not adapted to catch them." The ichthyologist dismisses this objection contemptuously. "Anything uncatchable by my net is ipso facto outside the scope of icthyological knowledge. In short, "what my net can't catch isn't fish." Or - to translate the analogy — "If you are not simply guessing, you are claiming a knowledge of the physical universe discovered in some other way than by the methods of physical science, and admittedly unverifiable by such methods. You are a metaphysician. Bah!" (Eddington, 1939)
} 
the result of normal people behaving in normal ways in normal organisations." Similar views are expressed in Rasmussen’s work:

“...risk management can only be discussed in depth when considering carefully the decision making involved in the normal operation of the hazardous processes posing potential for major accidents" (Rasmussen and Svedung, 2000).

\section{Theme 6: Enlarging the scope, context and boundaries of the systems approach}

Throughout his career Rasmussen sought to push at the boundaries of accepted wisdom within the fields of human factors/ergonomics and safety science. Whether this was challenging the orthodox view on human error in the 1960s and 70s (theme 5), arguing for more inter-disciplinarity (theme 8) or developing new tools and methods to analyse cognitive work, it remained a constant over the course of his career. Reason (2016) for example, singles out Rasmussen's contribution to the systems approach as a major step forward; in particular his control theoretic approach towards accidents (see also Leveson, this issue) and the 'Brownian motion' model (figure 4). As we have already pointed out (section 4.4), the 1997 paper serves to summarise and extend much of the Rasmussen's whole research programme, whilst at the same time providing a broader vison of what constitutes elements of, on the one hand, the landscape of safety research (themes 7 and 8), and on the other, the boundaries and scope of risk management and the systems approach (i.e. taking into account macro (e.g. political, regulatory) and micro (organisational culture, team and individual behaviour) factors). It is also clear that Rasmussen's impact on the systems approach and control theory cuts across a number of other themes (e.g. themes 5 and 10). Woods et al., (2010) points for example, to some of these inter-relationships:

"The focus of control theory is not on erroneous actions or violations, but on the mechanisms that such behaviours at a higher level of function abstraction mechanisms that turn these behaviours into normal, acceptable and even indispensable aspects of an actual, dynamic, daily work context." (Woods et al., 2010: 75).

One interesting theme for the future (theme 2) will be to assess how far we can go with this type of analysis (cf. Reason, 1999) and how far the boundaries of 
risk management can be extended in order to address more fully the politics and regulation of safety (Sagan, 1993). A similar challenge is how Rasmussen’s work can be adapted in order to cope with the demands and challenges involved in other domains of safety and topics of research which have attempted to incorporate aspects of ecology and environmental studies (e.g. food safety and security - Nayak and Waterson, 2016; sustainability - Thatcher and Yeow, 2016).

\section{Theme 7: Bridging between research, practice and design}

Although Rasmussen held visiting and research positions at various Universities (mainly from the 1980s onwards - Appendix 1), most of his career was spent at the Risø Laboratory. Much of his work reflects this 'practice-based' focus, particularly in terms of the various methods and tools he developed over the years. Larouzée, and Guarieir (2015) in their review of Reason’s Swiss Cheese Model concluded that "the success of the model is not so much due to appropriation of the work of the psychologist by the industrial community but to a complex process of co-production of knowledge and theories". Much the same might be said of Rasmussen's methodological contribution to human factors/ergonomics and safety science. There is other evidence to suggest that like the Swiss Cheese Model, Rasmussen's emphasis on the importance of graphical representation of accidents and complex work domains (e.g. in methods such as Accimap, CWA) has helped to bridge the gap between researchers and practitioners (Underwood and Waterson, 2013, 2014). Likewise, the fact that Rasmussen effectively produced what might be termed an 'adaptive toolbox' of methods, in the sense that these tools can be modified and altered to suit specific circumstances and contexts (McIlroy and Stanton, 2015) also lends them to transfer from academic environments into industry. We note however, that this may also impact upon the reliability and validity of the outputs produced by these methods (Sharples and Carayon, this issue). One of Rasmussen's basic theses was that the human operator compensates for what the designer did not and often could not foresee. Design studies and design programmes in universities increasingly appropriate human factors methods and there is evidence to suggest that approaches such as CWA and the decision ladder are increasingly used by the industrial and product design industries (e.g. Jenkins, 
2016a, 2016b). This may represent in itself another new direction for future research and practice (theme 2).

\section{Theme 8: The value of collaboration and inter-disciplinarity}

Towards the end of his career Rasmussen made a number of calls for closer collaboration between the various disciplines involved in risk management and safety. The 1997 paper (section 4.4) in particular, looks forward to the creation of a cross-disciplinary research community that can meet the challenge of coping with the rapidly changing demands of technological and societal change. Two decades after that call it is clear that some progress has been made and there is greater collaboration between researchers across the social and engineering sciences. The special issue for example, comprise authors from engineering, sociology, psychology and a number of other specialisms. It is also, however, clear that support and funding for cross-disciplinary meetings and research exchange has to too some extent dried up in the last few decades. Many of the papers and report written by Rasmussen came about as a result of meetings and conferences sponsored by organisations such as NATO and the World Bank (e.g, the annual Bad Homberg workshops on 'New Technology and Work' - Wilpert, 1987). Other researchers such as John Wilson (Wilson, 2014) and Andrew Hale (Hale, 2006; Waterson, 2016) have also pointed to the value of these opportunities for scientific exchange, as well as lamenting their demise. One of the side effects of these events, which are reflected in Rasmussen's work, was a spirt of pragmatism and open-mindedness. It is interesting to reflect that calls for these types of attitudes continue to be made within the fields of human factors and safety science (Haavik et al., 2016; Waterson and Catchpole, 2016). Rasmussen might be said to be a role model for inter-disciplinarity and one hope is that his work will continue to inspire others in the future.

\section{Extending the legacy}

We wish to thank all of the contributors to the special issue and hope that the 15 paper go some way towards preserving and celebrating the legacy of one of the most important figures in modern day human factors/ergonomics and safety science. Jens Rasmussen celebrated his $90^{\text {th }}$ birthday on May $11^{\text {th }} 2016$ and it is our intention that discussion and debate surrounding his work continues on well 
into the future. With this in mind, plans are in place to reconvene the legacy symposium at the next ODAM conference which will take place in 2017 in Banff, Canada (July $31^{\text {st }}-$ August $4^{\text {th }}$, 2017). In addition, a collection of Jens Rasmussen's reports and papers are being collated and we hope that a book may be produced out of these (i.e. similar to the 'Brunswik Reader' - Hammond and Stewart, 2001). Further information covering these activities in available through contacting the special issue editors.

Word count $=8,171$ words (excl., appendix and figures) 


\section{References}

Alexander, C. (1964), Notes on the Synthesis of Form. Cambridge, MA: Harvard Univ. Press.

Annett, J. and Duncan, K. D. (1967), Task analysis and training design. Occupational Psychology, 41, 211-221.

Argote, L. (1999). Organizational Learning: Creating, Retaining and Transferring Knowledge. Norwell, MA, Kluwer Academic Publishers.

Ashby, W.R. (1956). An Introduction to Cybernetics. London: Chapman \& Hall.

Bainbridge, L. (1969), The nature of the mental model in process control. Paper presented at the International Symposium on Man-Machine Systems, Cambridge, UK, September. Revised version published in E. Edwards and F.P. Lee (Eds., 1974), The Human Operator in Process Control. London: Taylor and Francis.

Bainbridge, L. and Sanderson, P. (1996), Verbal protocol analysis. In J.R. Wilson and E.N. Corlett, (Eds.) Evaluation of Human Work (2 ${ }^{\text {nd }}$ Edition). Taylor and Francis, London.

Bartlett, F.C. (1932). Remembering: A Study in Experimental and Social Psychology. Cambridge, England: Cambridge University Press.

Bartlett, F.C. (1958), Thinking: An Experimental and Social Study. Lodnon: Unwin.

Bennett, K. and Flach, J.M. (2011), Display and Interface Design: Subtle Science, Exact Art. Boca Raton: CRC Press.

Bertalanffy, L. von, (1969). General System Theory. New York: George Braziller, 
Broadbent, D. E., Fitzgerald, P., Broadbent, M.H.P. (1986). Implicit and explicit knowledge in the control of complex systems. British Journal of Psychology, 77, 33-50.

Borys, D., Else, D. and Leggett, S. (2009), The fifth age of safety: the adaptive age? Journal of Health and Safety, Research and Practice, 1, 19-27.

Bruner, J.S. (1973), Beyond the Information Given; Studies in the Psychology of Knowing. New York: W.W. Norton.

Bruner, J.S. (1986), Actual Minds, Possible Worlds. Harvard: Harvard University Press.

Burnham, J.C. (2009), Accident Prone - A History of Technology, Psychology and Misfits of the Machine Age. Chicago: Chicago University Press.

Carim Jr., G.C., Suarin, T.A., Havinga, J., Rae, A. and Dekker, S.W.A. (2016), Using a procedure doesn't mean following it: a cognitive systems approach to how a cockpit manages emergencies. Safety Science, 86, 147-157.

Clark, A.J. (1997), Being There: Putting Brain, Body and World Together Again. London: MIT Press.

Cook, R.I. (2014), Rasmussen, engineering, and the influence of indicator diagrams. Presentation at the Adjunct Symposium to ODAM 2014, August 20th - 21st 2014.

Craik, K.J.H. (1943), The Nature of Explanation. Cambridge: Cambridge University Press.

Crossman, E.R.F.W. and Cooke, J.E. (1962), Manual control of slow-response systems, paper presented at the International Congress of Human Factors in Electronics, Long Beach, CA.. Reprinted in E. Edwards and F. Lees, (1974) The Human Operator in Process Control. London: Taylor and Francis. 
Dekker, S.W.A. (2011). Drift into Failure: From Hunting Broken Components to Understanding Complex Systems. Farnham, UK, Ashgate.

Dennett, D.C. (1971), Intentional systems, Journal of Philosophy, 68, 4, 87-106

Dictionary of Scientific Thought (2008), James Jerome Gibson. Available at http://www.encyclopedia.com/topic/James_Jerome_Gibson.aspx (last accessed 6th September, 2016).

Eddington, A. (1939), The Philosophy of Physical Science. New York: Cambridge University Press.

Ferguson, E.S. (1992), Engineering and the Mind's Eye. Cambridge, Mass.: MIT Books.

Fitts, P.M. and Posner, M.I. (1962), Human Performance. Belmont, CA: BrooksCole.

Flach, J.M., and Voorhorst, F. (2016), What Matters? Putting Common Sense to Work. Dayton, Ohio: Wright State University Libraries. http://corescholar.libraries.wright.edu/books/127/

Gibson, J.J. (1966). The Senses Considered as Perceptual Systems. Boston: Houghton Mifflin.

Goodstein, L.P., Andersen, H.B. and Olson, S.E. (1988, eds.), Tasks, Errors and Mental Models: A Festschrift to Celebrate the $60^{\text {th }}$ Birthday of Professor Jens Rasmussen. London: Taylor and Francis.

Gregory, R.L. (1987), Egon Brunswick. Entry in R.L. Gregory (Eds.) The Oxford Companion to the Mind. Oxford: OUP.

Guldenmund, F. W. (2000). The nature of safety culture: a review of theory and research. Safety Science, 34, 215-257. 
Haavik, T.K., Sntonsen, S., Rosness, R. and Hale, A.R. (2016), HRO and RE: a pragmatic perspective. To appear in Safety Science.

Hale, A.R. (2006), Method in your madness: system in your safety. Afscheidsrede, Technical University Delft, 15 ${ }^{\text {th }}$ September, 2006.

Hale, A.R. and Hale, M. (1972), A review of the industrial accident research literature. Research paper for the Robens Committee on Safety and Health at Work. National Institute of Industrial Psychology. London: HMSO.

Hale, A.R. and Borys D. (2013a), Working to rule or working safely? Part 1: A state of the art review. Safety Science, 55, 207-221.

Hale, A.R. and Borys D. (2013b), Working to rule or working safely? Part 2: The management of safety rules and procedures. Safety Science, 55, 222-231.

Hale A.R., Kirwan B. and Guldenmund F. (1996), Capturing the river: multilevel modelling of safety management. In Second ICPO Conference on Human Factors and Safety, Berlin, November. Later published in J. Misumi, B. Wilpert and R. Miller, (1999, Eds.) Nuclear Safety: a Human Factors Perspective. London. Taylor and Francis.

Hall, S. (1999), Hidden Dangers: Railway Safety in the Era of Privatisation. Shepperton: Ian Allan.

Hammond, K.R. and Stewart, T.R. (2001, Eds,), The Essential Brunswik. Cary, NC: Oxford University Press.

Harvey, E.J., Waterson, P.E. and Dainty, A.R.J. (in press), Applying HRO and resilience engineering to construction: Barriers and opportunities. To appear in Safety Science http://dx.doi.org/10.1016/j.ssci.2016.08.019

Holden, R.H. (2009), People or systems? To blame is human. The fix is to engineer. Professional Safety, 54, 34-41. 
Hollnagel, E. and Woods, D.D. (1983), Cognitive systems engineering: new wine in old bottles. International Journal of Man-Machine Studies, 18, 583-600.

Hollnagel, E., Woods, D.D. and Leveson, N.G. (2006, Eds), Resilience Engineering: Concept and Precepts. Farnham: Ashgate.

Hollnagel, E., Mancini, G. and Woods, D.D. (1986, Eds.), Intelligent Decision Support in Process Environments (Proceedings of the NATO Advanced Study Institute Intelligent Decision Support in Process Environments in Process Environments, San Miniato, Italy, September 16-27, 1985. Berlin: Springer Verlag.

Hollnagel, E., Wears, R.L. and Braithwaite, J. (2015), From Safety-I to Safety-II: A White Paper. Report available from:

http://resilienthealthcare.net/onewebmedia/WhitePaperFinal.pdf (last accessed August $15^{\text {th }}$ 2016).

Hunt, R.M. and Rouse, W.B. (1984), A fuzzy rule-based model of human problem solving. IEEE Transactions on Systems, Man, and Cybernetics, 14, 112120.

Hutchins, E. (1995), Cognition in the Wild. Cambridge, MIT: Bradford Books.

Jenkins, D.P. (2016a). Cognitive Work Analysis in the wild. Human Factors in Complex Systems. 7-8 June 2016 Nottingham, UK.

Jenkins, D.P. (2016b). Using the decision ladder to reach a better design. The Ergonomics Society Annual Conference. 19-21 April 2016 Daventry, UK

Johnson-Laird, P.N. (1983), Mental Models. Cambridge: Cambridge University Press. 
Karsh, B-T., Waterson, P.E. and Holden, R. (2014), Crossing levels in systems ergonomics: a framework to support 'mesoergonomic' inquiry. Applied Ergonomics, 45, 45-54.

Kirwan, B., Hale, A. and Hopkins, A. (2002, Eds.), Changing Regulation -

Controlling Risks in Society. London: Pergamon.

Klein, G., Orasanu, J., Calderwood, R. and Zsambok, C.E. (1994, Eds.), Decision-Making in Action: Models and Methods. Norwood, NJ: Ablex.

Kletz, T. (1993), Lessons from Disaster: How Organisations Have No Memory and Accidents Recur. Rugby: Institution of Chemical Engineers.

Kontogiannis, T. and Malakis, S. (2012), Recursive modeling of loss of control in human and organizational processes: A systemic model for accident analysis. Accident Analysis and Prevention, 48, 303-316.

Larkin, J.H. and Simon, H.A. (1987), Why a diagram is (sometimes) worth ten thousand words. Cognitive Science, 11, 65-99.

Larouzée, J. and Guarnieri, F, (2015), From theory to practice: itinerary of Reason's Swiss Cheese model. In L. Podofillini, B. Sudret, B. Stojadinovic, E. Zio, and W Kröger. Proceedings of ESREL 2015, Sep 2015, Zürich, Switzerland.

Leplat, J. and Rasmussen, J. (1984), Analysis of human errors in industrial incidents and accidents from improvement of work safety. Accident Analysis and Prevention, 16, 77-88.

Li, C., Waterson, P.E., Read, G. and Tang, T. (in preparation), Comparing the systemic accident analysis properties of STAMP and Accimap. Manuscript in preparation, Human Factors and Complex Systems Group, Loughborough University. 
Le Coze, J.C. (2013), New models for new times. An anti dualist move. Safety Science. 59. 200-218.

Le Coze, J.C. (2015), Reflecting on Jens Rasmussen’s legacy, a strong program for a hard problem. Safety Science. 71. 123-141.

Le Coze, J.C. (2016a), Vive la diversité! High Reliability Organisation (HRO) and Resilience Engineering (RE). Safety Science. doi:10.1016/j.ssci.2016.04.006

Le Coze, J.C. (2016b), Trente and d'accidents. Le nouveau visage des risques sociotechnologiques. Toulouse : Octarès.

Le Coze, J.C. (Forthcoming), Managing the unexpected. In Muller, N., Svensson, Rollenhagen, C. (eds) Handbook of Safety Principles.

Lévi-Strauss, C. (1966), The Savage Mind. Chicago, IL: University of Chicago Press.

Lindsay, P.H. And Norman, D.A. (1972), Human Information Processing: An Introduction to Psychology. New York: Academic Press.

Macrae, C. (2014), Early warnings, weak signals and learning from healthcare disasters. BMJ: Quality and Safety, 23, 6, 440-5

Marais, K. Saleh, J.H. and Leveson, N.G. (2006), Archetypes for organizational safety. Safety Science, 44, 565-582.

Marr, D. (1982), Vision. San Francisco: Freeman.

McIlroy, R.C. and Stanton, N.A. (2015), Ecological interface design two decades on: whatever happened to the SRK taxonomy? IEEE Transactions on HumanMachine Systems, 45, 145-163.

Miller, G.A., Galanter, E. and Pribram, K. (1960), Plans and the Structure of Behaviour. New York: Holt, Rinehart \& Winston. 
Minsky, Marvin (1975). A framework for representing knowledge. In P. Winston (Ed.) The Psychology of Computer Vision, New York: McGraw-Hill.

Nayak, R. and Waterson, P.E. (2016), 'When Food Kills': A sociotechnical systems analysis of the UK Pennington 1996 and 2005 e.Coli O157 outbreak reports. Safety Science, 86, 26-37.

Neisser, U. (1967), Cognitive Psychology. New York: Appleton-Century-Crofts.

Neisser, U. (1976), Cognition and Reality. San Francisco: W.H. Freeman.

Newell, A. (1980), Reasoning, problem solving and decision processes: the problem space as a fundamental category. In R.S. Nickerson (Ed.) Attention and Performance VIII. Hillsdale, NJ: Lawrence Erlbaum.

Newell, A. and Simon, H.A. (1972), Human Problem Solving. Englewood Cliffs, NJ: Prentice and Hall.

Nielsen, H. (1998, Ed.), Til samfundets tarv - Forskningscenter Risøs historie. Publisher: Forskningscenter Risø, Denmark.

Norman, D.A. (1981), Categorisation of action slips. Psychological Review, 88, $1-15$.

Norman, D.A. (1986), Cognitive Engineering. In D.A. Norman and S.W. Draper (Eds.), User Centred System Design. Hillsdale, NJ: Erlbaum.

Norman, D.A. and Shallice, T. (1986). Attention to action: willed and automatic control of behaviour. In R.J. Davison, G.E. Schwartz, and D. Shapiro (Eds.), Consciousness and Self-Regulation. (Volume 4) New York: Plenum.

Perrow, C. (1984), Normal Accidents. New York: Basic Books. 
Pink, S., Waterson, P.E., Dainty, A., Cheyne, A., Haslam, R., Gibb, A., Morgan, J., Hartley, R., Finneran, A. and Bust, P. (in press), Interdisciplinary research for occupational health and safety knowledge. To appear in Policy and Practice in Health and Safety.

Rid, T. (2016), Rise of the Machines: The Lost History of Cybernetics. London: Scribe Publications.

Rasmussen, J. (1968), On the communication between operators and instrumentation in automatic process plants. Report: Risø-M-686. Reprinted in E. Edward. and F.P. Lees (Eds., 1974), The Human Operator in Process Control. London: Taylor and Francis.

Rasmussen, J. (1974), The human data processor as a system component: bits and pieces of a model. Report No. Risø-M-1722. Roskilde, Denmark: Danish Atomic Energy Commission.

Rasmussen, J. (1980), The human as a systems component. In H.T. Smith and T.R.G. Green (Eds.), Human Interaction with Computers. London: Academic Press.

Rasmussen, J. (1982), Human errors. A taxonomy for describing human malfunction in industrial applications. Journal of Occupational Accidents, 4, 311333.

Rasmussen, J. (1985), The role of hierarchical knowledge representation in decision making and system management. IEEE Transactions on Systems, Man, and Cybernetics, 15, 234-243.

Rasmussen, J. (1986). Information Processing and Human-Machine Interaction: An Approach to Cognitive Engineering. New York: North Holland. 
Rasmussen, J. (1999), Preface. In K.J. Vicente (Ed.), Cognitive Work Analysis: Productive, and Healthy Computer-Based Work. Boca Raton: CRC Press.. Boca Raton: CRC Press.

Rasmussen, J. (2003), The role of error in organizing behaviour. Quality and Safety in Healthcare, 12, 377-385.

Rasmussen, J. and Batstone, R. (1991), Towards improved safety control and risk management. Report. Washington D.C.: World Bank.

Rasmussen, J. and Vicente, K.J. (1989), Coping with human errors through system design: implications for ecological interface design. International Journal of Man-Machine Studies, 31, 517-534.

Rasmussen, J. and Svedung, I. (2000), Proactive Risk Management in a Dynamic Society. Karlstad: Swedish Rescue Services Agency.

Rasmussen, J. Pejtersen, A.M. and Goodstein, L.P. (1994), Cognitive Systems Engineering. New York: Wiley.

Reason J.T. (1990), Human Error. Cambridge: Cambridge University Press.

Reason J.T. (1997) Generic Error-Modelling System (GEMS): A cognitive framework for locating common human error forms. In J. Rasmussen, K. Duncan and J. Leplat (Eds.), New Technology and Human Error. New York: Wiley.

Reason J.T. (1999) Are we casting the net too widely in our search for the factors contributing to errors and accidents? In J. Misumi, B. Wilpert and R. Miller (Eds.) Nuclear Safety: An Ergonomics Perspective. Boca Raton: CRC Press.

Reason, J.T. (2016), Organizational Accidents Revisited. Farnham: Ashgate. 
Reason J.T., Parker, D, and Lawton, R. (1998), Organizational controls and safety: The varieties of rule-related behaviour. Journal of Occupational and Organizational Psychology. 71, 289-304.

Robertson, K., Black, J. Grand-Clement, S. and Hall, A. (2016), Human and Organisational Factors in Major Accidents. RAND Europe Report. Available at: http://www.rand.org/pubs/research_reports/RR1512.html (last accessed September 6th, 2016.

Rosenbluth, A., Wiener, N. and Bigelow, J. (1943), Behaviour, purpose and teleology. Philosophy of Science, 10, 18-24.

Ryan, B. and Waterson, P.E. (2016), Working on the border: Applying cross disciplinary learning to complex systems and safety. Paper presented at the Human Factors in Complex Systems Symposium, Nottingham, June.

Sagan, S.D. (1993), The Limits of Safety. Princeton: Princeton University Press.

Scaife, M. and Rogers, Y. (1996) External cognition: how do graphical representations work? International Journal of Human-Computer Studies, 45, $185-213$

Schank, R.C. and Abelson, R.P. (1977). Scripts, Plans, Goals and Understanding. Hillsdale, NJ: Erlbaum.

Shannon, C. (1948), A mathematical theory of communication. Bell System Technical Journal, 27 (July and October): 379-423, 623-656.

Simon, H. (1969), The Sciences of the Artificial. MIT Press, Cambridge, Mass, (1st edition).

Sheridan, T.B. (2003), Human error. Quality and Safety in Healthcare, 12, 383385. (Published as a commentary to Rasmussen, 2003). 
Snook, S.A. (2000), Friendly Fire: The Accidental Shooting Down of U.S. Black

Hawks Over Northern Iraq. Princeton: Princeton University Press.

Stevens, K.A. (2012), The vision of David Marr. Perception, 41, 1061-1072.

Tanner, W. P., Jr. and Swets, J. A. (1954). A decision-making theory of visual detection. Psychological Review, 61, 401-409.

Thatcher, A. and Yeow, P.H.P. (2016). Human factors for a sustainable future. Applied Ergonomics, 57, 1-7.

Turner, B.A. (1978), Man-Made Disasters. London: Wykeham Science Press.

Tversky, A. and Kahneman, D. (1974), Judgement under uncertainty: heuristics and biases. Science, 185, 1123-1124.

Underwood, P. and Waterson, P.E. (2013), Systemic accident analysis: examining the gap between research and practice. Accident Analysis and Prevention, 55, 154-164.

Underwood, P. and Waterson, P.E. (2014), Systems thinking, the Swiss Cheese model and accident analysis: a comparative systems analysis of the Grayrigg train derailment using the ATSB, Accimap and STAMP models. Accident Analysis and Prevention, 68, 75-94

Vicente, K.J. (1997), A history of cognitive engineering at Risø, Proceedings of the Human Factors and Ergonomics Society $41^{\text {st }}$ Annual Meeting, 210-214.

Vicente, K.J. (1999), Cognitive Work Analysis: Toward Safe, Productive and Healthy Computer-based Work. Mahwah, NJ: Lawrence Erlbaum.

Vicente, K.J. and Rasmussen, J. (1992), Ecological interface design: theoretical foundations. IEEE Transactions on Systems, Man, and Cybernetics, 22, 589-606. 
Waterson, P.E. (2016), Interview with Professor Andrew Hale. May $27^{\text {th }} 2016$. To appear in The Psychologist.

Waterson. P.E., Robertson, M.M., Cooke, N.J. Militello, L, Roth, E. and Stanton, N.A. (2015), Defining the methodological challenges and opportunities for an effective science of sociotechnical systems and safety. Ergonomics, 58, 650-8.

Waterson, P.E. and Catchpole, K. (2016), Human factors in healthcare: welcome progress, but still scratching the surface. BMJ: Quality and Safety, 25: 480-484

Waterson, P.E., Baber, C. and Li, C. (2016), How Viable is STAMP? Comparing STAMP with Beer's Viable Systems Model (VSM) using the China-Yongwen railway accident as an example. Paper presented at the Human Factors in Complex Systems Symposium (HFICS), Nottingham, June.

Waterson, P.E., Mumford, S. and Golightly, D. (2016), Accidents and causation - some unresolved philosophical issues for human factors and complex systems. Paper presented at the Philosophy, Ergonomics and Applications in Complex Human Systems Symposium (PEACHS 2016), Nottingham, June.

Wilson, J.R. (2014), Fundamentals of systems ergonomics/human factors. Applied Ergonomics, 14, 5-13.

Wiener, N. (1948), Cybernetics or Control and Communication in the Animal and the Machine. Cambridge: MIT Press.

Wilpert, B. (1987-), New Technology and Work Series. London: Wiley.

Wagenaar, W.A. and Reason, J.T. (1990), Types and tokens in accident causation. Ergonomics, 33, 1365-1375.

Weick, K. E., and Sutcliffe, K. M. (2007). Managing the Unexpected: Resilient Performance in an Age of Uncertainty ( ${ }^{\text {nd }}$ Edition). San Francisco: Jossey-Bass. 
Woods, D.D., Dekker, S.W.A., Cook, R.I., Johannesen, L. and Sarter, N. (2013), Behind Human Error. Farnham: Ashgate.

Zwetsloot, G.I.J.M., Aaltonen, M., Wybo, J-L, Saari, J., Kines, P. and Beeck, R.D. (2013), The case for research into the zero accident vision. Safety Science, 58, 41-48.

Zwetsloot, G.I.J.M., Kines, P., Wybo, J-L, Ruotsala, R., Drupsteen, L. and Bezemer, R.A. (2017, in press), zero accident vision based strategies in organisations: Innovative perspectives. To appear in Safety Science, 
Appendix 1: Jens Rasmussen career timeline

\begin{tabular}{|c|c|}
\hline Date & Event \\
\hline 1926 & Ribe, Denmark \\
\hline 1950 & $\begin{array}{l}\text { M.Sc. degree with honours in electronic engineering from Technical } \\
\text { University of Copenhagen }\end{array}$ \\
\hline 1956 & $\begin{array}{l}\text { Joins the Atomic Energy Commission's Research Establishment Risø, } \\
\text { now Risø National Laboratory }\end{array}$ \\
\hline 1962 & $\begin{array}{l}\text { Appointed Head of the Electronics Department at Risø (continues } \\
\text { until 1987) }\end{array}$ \\
\hline 1962 & Elected member of the Danish Academy of Technical Sciences \\
\hline 1972 & $\begin{array}{l}\text { LK-NES Industrial Prize for "outstanding contributions to research on } \\
\text { man-machine interfaces" }\end{array}$ \\
\hline $1979-81$ & $\begin{array}{l}\text { Chairman of group of experts on human error analysis under CSNI, } \\
\text { the Committee on Safety of Nuclear Installations of OECD }\end{array}$ \\
\hline $1981-83$ & Member of NATO Special Program Panel on Human Factors \\
\hline 1981-83 & $\begin{array}{l}\text { Visiting Professor at "Center for Man-Machine Systems Research", } \\
\text { Department of Industrial Engineering, Georgia Institute of } \\
\text { Technology }\end{array}$ \\
\hline $\begin{array}{l}1983- \\
\text { onwards }\end{array}$ & $\begin{array}{l}\text { Serves on several expert panels on human-machine interaction and } \\
\text { human error issues under National Research Council, National } \\
\text { Academy of Sciences, Washington, USA }\end{array}$ \\
\hline $1987-92$ & $\begin{array}{l}\text { Research professor of cognitive engineering at Risø National } \\
\text { Laboratory and Technical University of Copenhagen }\end{array}$ \\
\hline 1987 & $\begin{array}{l}\text { Distinguished Foreign Colleague Award of the American Human } \\
\text { Factors Society for "outstanding contributions to the human factors } \\
\text { field." }\end{array}$ \\
\hline 1988 & $\begin{array}{l}\text { Publication of a Festschrift to celebrate Rasmussen's } 60^{\text {th }} \text { birthday } \\
\text { (Goodstein, Andersen and Olsen, 1988) }\end{array}$ \\
\hline 1994 & $\begin{array}{l}\text { Norbert Wiener Award from IEEE Society of Systems, Man, and } \\
\text { Cybernetics society for "truly outstanding contributions to research } \\
\text { and scholarship in cognitive engineering, human factors, ecological } \\
\text { interface design and the skill-rule-knowledge paradigm for human } \\
\text { information processing and judgment." }\end{array}$ \\
\hline 1997 & Honorary degree (Dr.-Ing. e.h.), Technical University of Berlin. \\
\hline 1999 & Honorary degree (Dr. Sc. h.c.), University of Toronto. \\
\hline 2000 & Elected Fellow of the Human Factors and Ergonomics Society \\
\hline 2013 & $\begin{array}{l}\text { Elected Foreign Member National Academy of Engineering (National } \\
\text { Academy of Sciences) } \\
\text { Retires }\end{array}$ \\
\hline
\end{tabular}


Figure 1: SRK Framework (Adapted from Rasmussen, 1983)

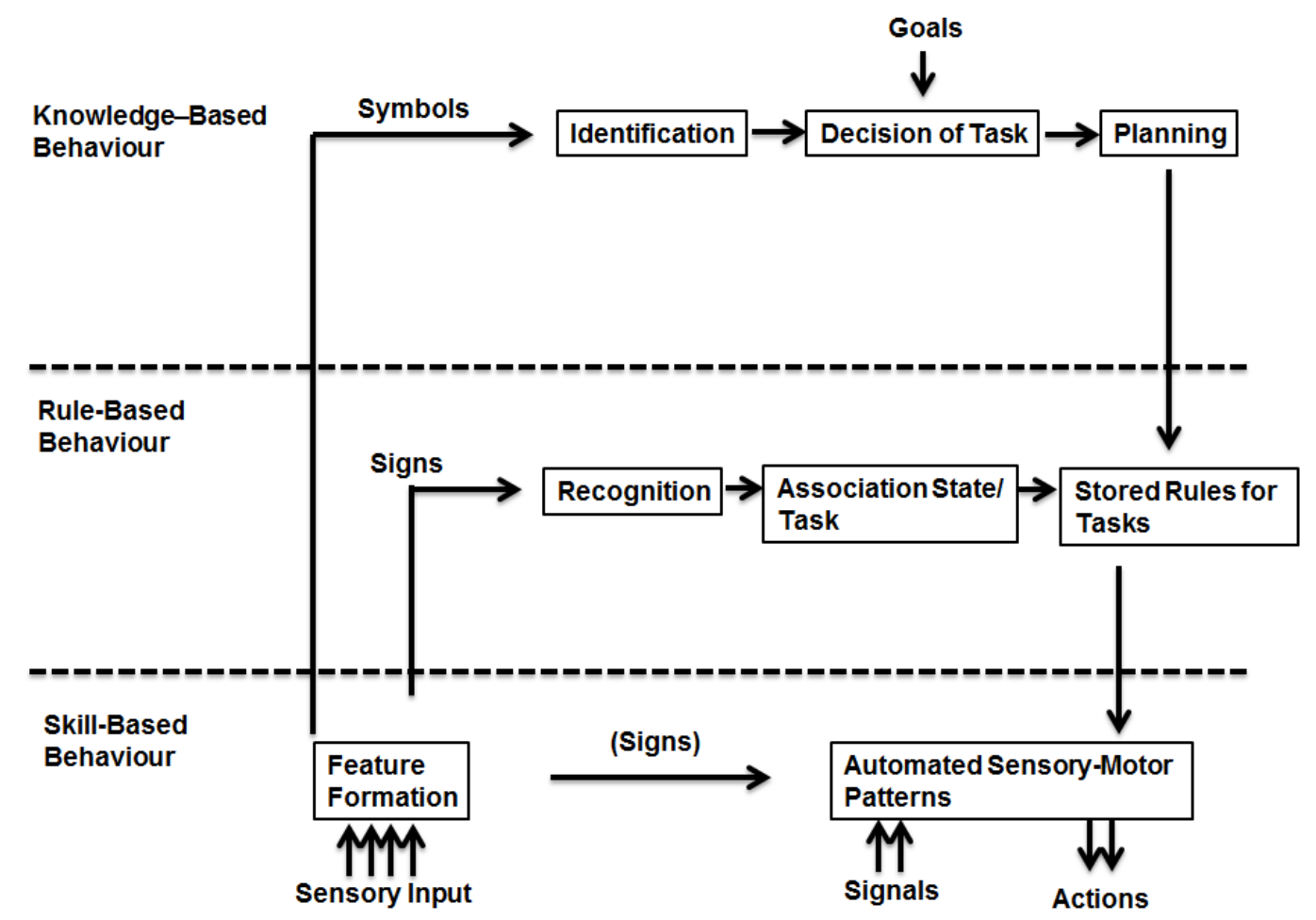


Figure 2: The abstraction hierarchy (Redrawn from Rasmussen, 1983:262)

\begin{tabular}{|l|l|}
\hline \multicolumn{2}{|c|}{ Levels of Abstraction } \\
Functional Purpose \\
\hline Production flow models, \\
system objectives
\end{tabular}


Figure 3: Timeline - 'Macro’ and ‘micro’ aspects of the work of Jens Rasmussen

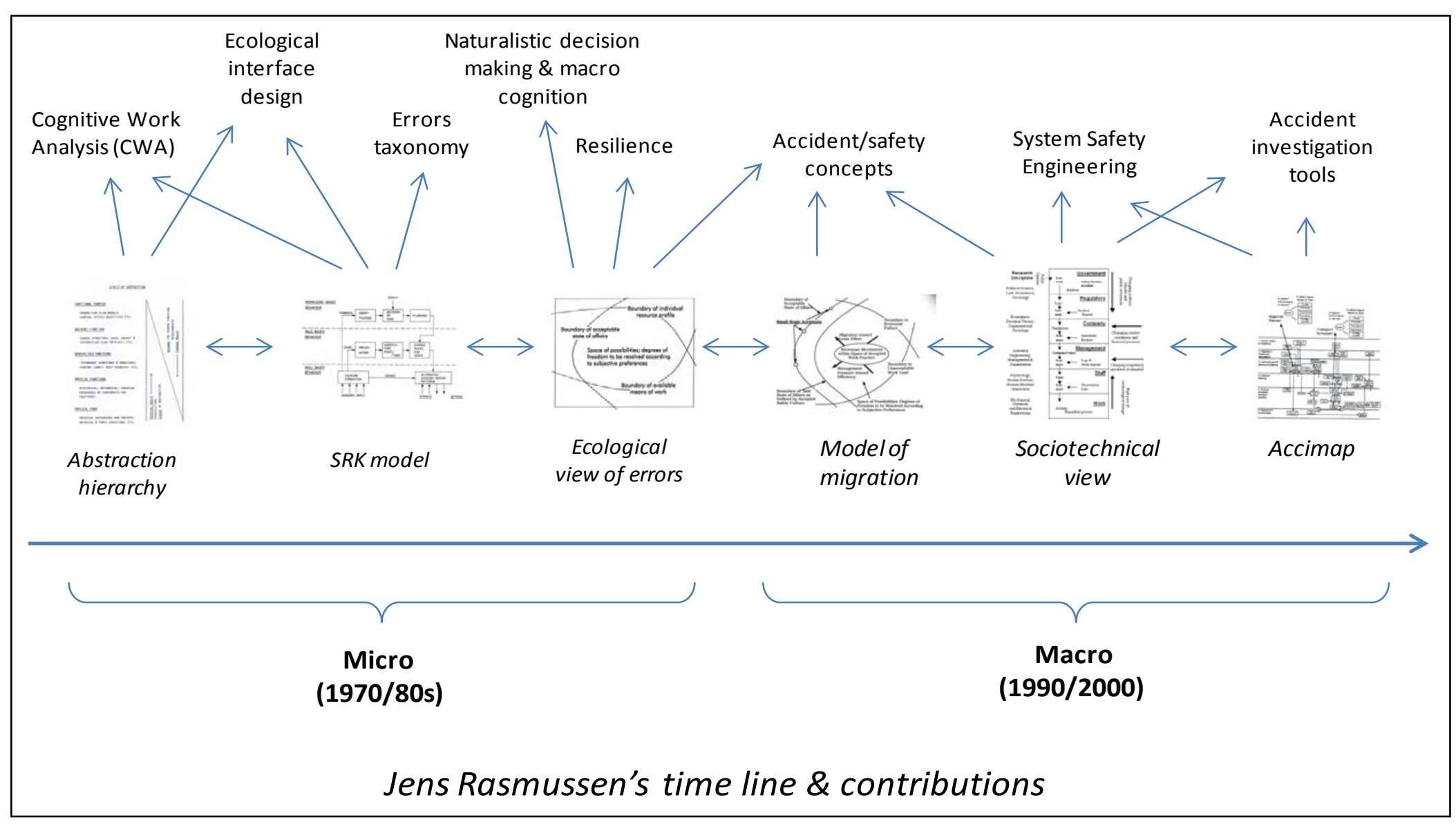


Figure 4: 'Brownian motion’ model of boundaries of acceptable performance (Rasmussen, 1997:190)

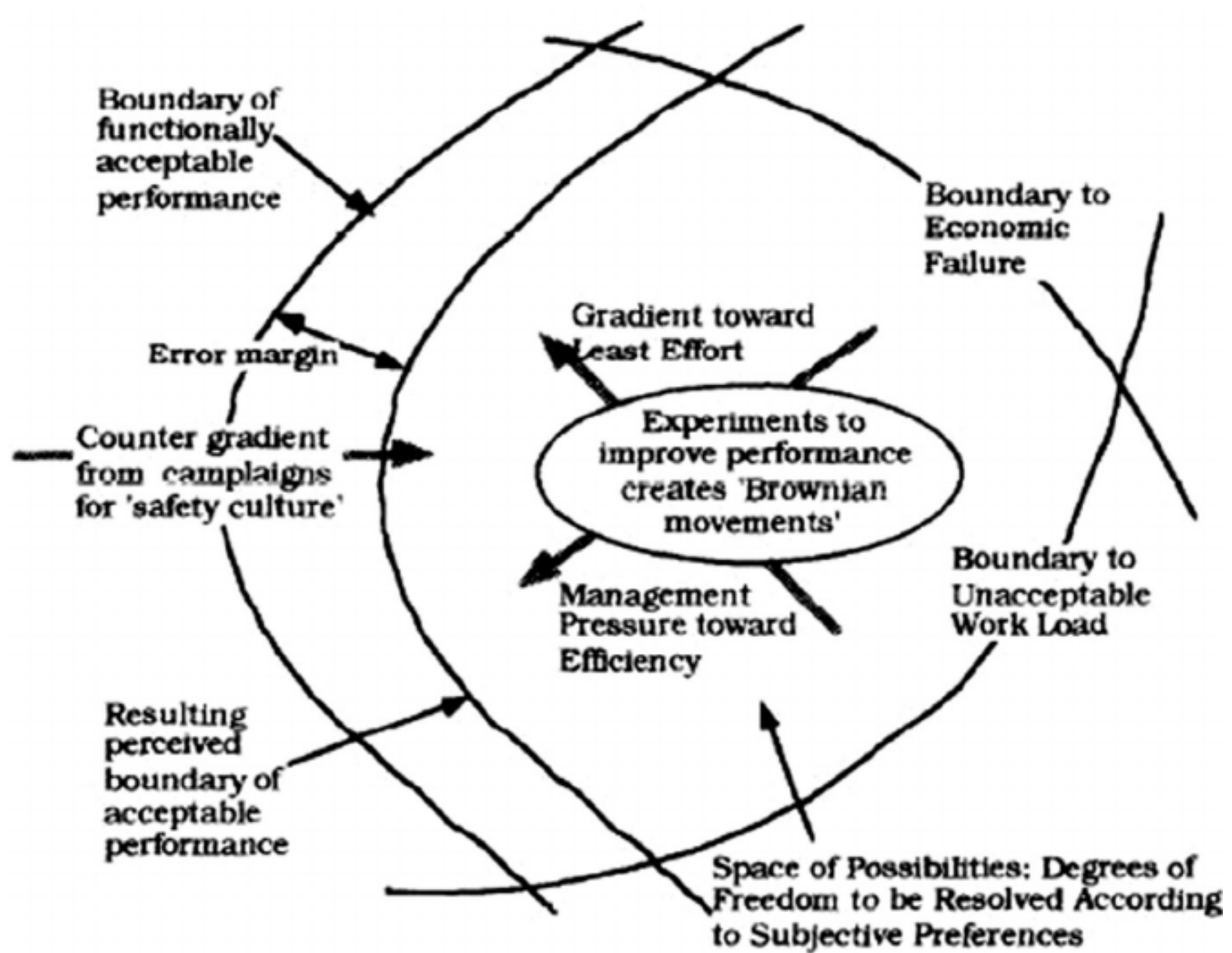


Figure 5: Early influences, societal developments and legacy

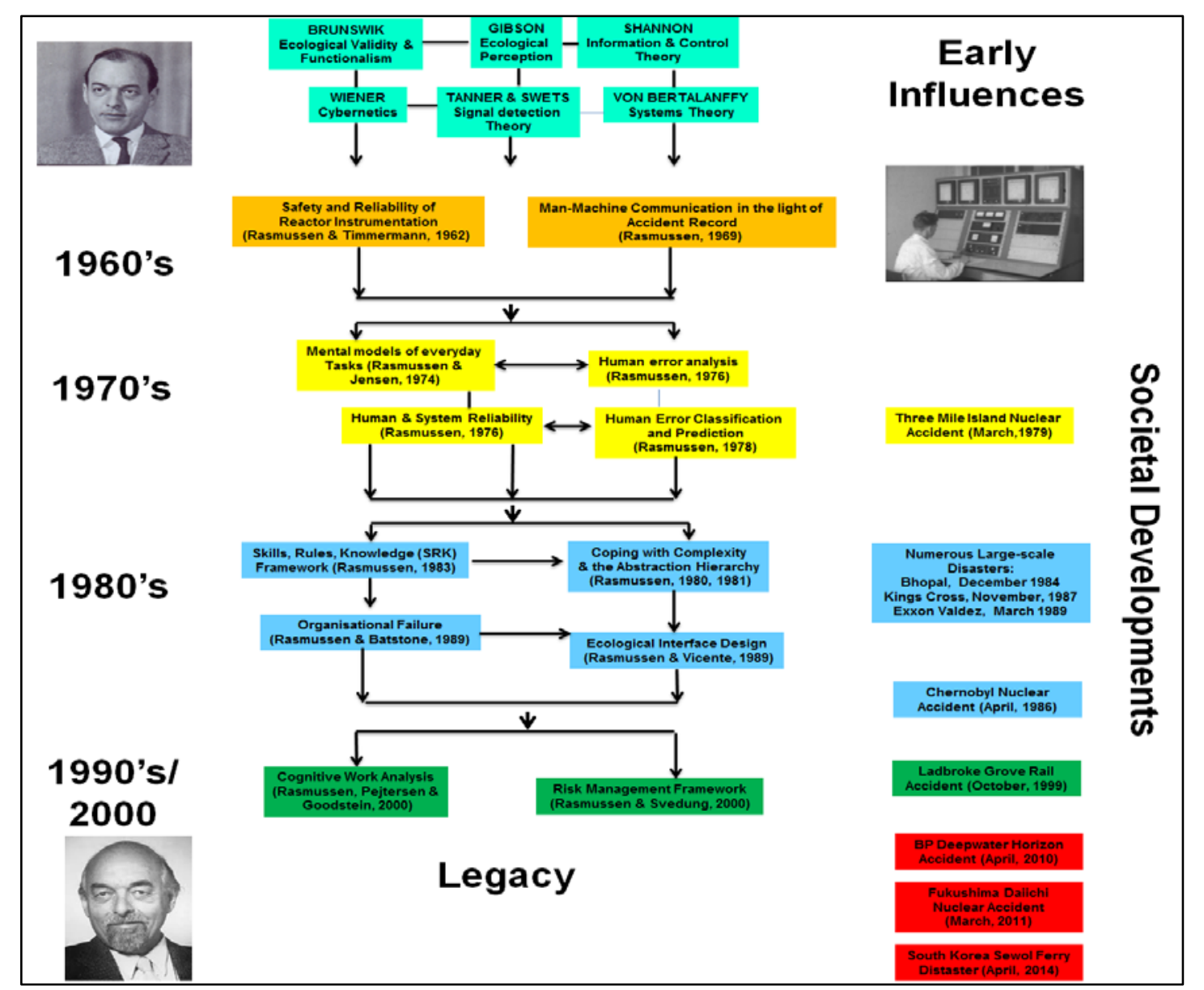

